\title{
The Castellan Student Paper Award
}

The Society for Computers in Psychology's student paper award has been named in honor and memory of N. John Castellan, Jr. The SCiP Steering Committee made this decision because John dedicated much of his life to three goals that we hope the students will pursue: educating others, developing technological innovations for research and education, and serving our Computer Society.

John served SCiP in many capacities. These included his role on the steering committee for 15 years, working on the SCiP program committee for several years, and being its chairman three times. He was SCiP's president for the 1979-1980 term.

John's innovative technological contributions were reported in 18 articles in BRMIC and 10 talks at SCiP meetings. These contributions included several on instructional computing, as John wanted to facilitate the work that today's students must do to become tomorrow's researchers, teachers, and scientific policy makers. John also provided us with numerous research tools for running valid and reliable experiments, as well as for analyzing the data from those computer-based experiments. This was because John understood the importance of state-of-the-art technology for facilitating quality research in the psychological sciences.

On the education front, John was constantly teaching others, both faculty and students. This included 20 years of involvement with CONDUIT and EDUCOM, organizations dedicated to educational uses of computers. John was a personal mentor to other faculty, particularly junior faculty, within his own research areas, which were indeed quite broad: learning, problem solving, decision making, cognitive processes and strategies, mathematical and computer modeling, and developing new statistical procedures. He encouraged other senior faculty to play strong roles in supporting the next generation of researchers and educators.

The SCiP Board members hope that the winners of the Castellan student paper award will not only strive for the research and educational excellence achieved by John Castellan, but also place a high priority on the values of personal integrity and generosity that John exemplified in his interaction with others. It is our pleasure to present the first Castellan award to Edward Colet for his paper on "Visualization of Multivariate Data: Human Factors Considerations," which is printed in Session 9 of this issue. 